\title{
Availability and use of designated hospital pens in Danish dairy herds
}

Houe, Hans; Thomsen, P. T.; Williams, Charlotte Amdi; Herskin, M. S.; Forkman, Björn; Jensen, M. B.

Published in:

Animal Welfare

DOI:

10.7120/09627286.25.1.069

Publication date:

2016

Document license:

Other

Citation for published version (APA):

Houe, H., Thomsen, P. T., Williams, C. A., Herskin, M. S., Forkman, B., \& Jensen, M. B. (2016). Availability and use of designated hospital pens in Danish dairy herds. Animal Welfare, 25(1), 69-71.

https://doi.org/10.7120/09627286.25.1.069 


\title{
Availability and use of designated hospital pens in Danish dairy herds
}

\author{
H Houe* ${ }^{* \dagger}$, PT Thomsen ${ }^{\ddagger}$, C Amdi ${ }^{\dagger}$, MS Herskin ${ }^{\ddagger}, B$ Forkman ${ }^{\dagger}$ and MB Jensen ${ }^{\ddagger}$
}

\author{
Department of Large Animal Sciences, University of Copenhagen, Grønnegårdsvej 8, DK-1870 Frederiksberg C, Denmark \\ ₹ Department of Animal Science, Aarhus University, AU-Foulum, Blichers Allé 20, DK-8830 Tjele, Denmark \\ * Contact for correspondence and requests for reprints: houe@sund.ku.dk
}

\begin{abstract}
The objective of this study was to describe the availability and use of designated hospital pens in Danish dairy herds and to analyse the association between availability and use of hospital pens and the herd-level incidence of reported disease treatments. Hospital pens were divided into either 'individual hospital pens' designed for only one animal or 'group hospital pens' designed for two or more animals. Questionnaires were sent to 350 dairy cattle herd owners. These questionnaires focused on four animal categories: dairy cows, heifers, males six months or older, and calves younger than six months. Depending on the category of animal, between 50 and $82 \%$ of the herds had access to individual hospital pens and between 39 and $65 \%$ of the herds had access to group hospital pens. Between nine and $24 \%$ of the herds did not have access to any type of hospital pens. The availability of hospital pens was generally higher for dairy cows than the other animal groups. There were significantly more reported treatments for hooflleg disorders in herds with one or more cows in hospital pens at the day of visit.
\end{abstract}

Keywords: animal welfare, dairy cattle, Denmark, disease incidence, hooflleg disorders, hospital pen

\section{Introduction}

Animals in poor health are known to alter their behaviour as part of an evolutionary strategy facilitating their survival (Aubert 1999; Dantzer \& Kelley 2007) and such behavioural changes have persisted in farm animals (Weary et al 2009). Dairy cows suffering from infectious disease reduce their activity and feed intake (Huzzey et al 2007; Fogsgaard et al 2012a). One way to facilitate the recovery of diseased individuals may be to promote such sickness behaviour by use of hospital pens or 'special-need-areas' providing a soft lying surface (Jensen et al 2015) and allowing isolation seeking and facilitating inactivity (Proudfoot et al 2014). Furthermore, housing sick and injured animals in special pens often facilitates human supervision. It is therefore recommended, and in some countries mandatory, that hospital pens are available in dairy herds. In Denmark, for instance, access to hospital pens will be mandatory in dairy herds from 2016 (Law nr 520, 26/05/2010; Anonymous 2014).

A questionnaire survey in Iowa, USA, showed that $79 \%$ of the 123 dairy farmers that responded had special needs facilities allowing diseased animals to be moved away from the home pen, and $49 \%$ of the farmers had a designated hospital area for diseased animals (Fogsgaard et al 2012b). Information on the availability of hospital pens in dairy herds is otherwise limited. As hospital pens could be an easily measured, resource-based welfare indicator, it is relevant to investigate if the availability and use of hospital pens is asso- ciated with animal-based measures, such as disease treatments. The objective of the present study was to describe the availability and use of designated hospital pens in Danish dairy herds, based on a questionnaire survey sent to Danish farmers, and to study whether the availability and/or use of hospital pens for dairy cows was associated with the incidence of reported disease treatments in the herds.

\section{Materials and methods}

The study population consisted of 350 Danish dairy cattle herds. The herds were randomly selected by the Danish Veterinary and Food Administration for another study on animal welfare control (Bennedsgaard et al 2014). A written questionnaire on the availability and use of hospital pens was delivered to the farmer at a herd visit, and returned to Aarhus University via mail. Questions were addressed separately for the four animal categories: dairy cows, heifers (females older than six months and before first calving), males six months old or older, and calves younger than six months. Hospital pens were divided into being either 'individual hospital pens' designed for only one animal or 'group hospital pens' designed for two or more animals. For herds with dairy cows, additional information on the incidence of reported disease treatments, cow mortality, herd size, bulk milk somatic cell count (BMSCC), milk yield per cow-year, and whether the farm was organic or conventional was extracted from the Danish Cattle Database (DCD). The 
Table I Outcome and explanatory variables included in the statistical analysis on whether availability or use of hospital pens was associated with the incidence of recorded disease treatments.

\begin{tabular}{ll}
\hline Outcome & Explanatory variables \\
\hline Reported treatment incidence total & $\begin{array}{l}\text { Availability of hospital pen, annual cow mortality rate, herd size, BMSCC, milk } \\
\text { yield per cow-year, organic }\end{array}$ \\
Reported treatment incidence for hoof/leg disorders & $\begin{array}{l}\text { Availability of hospital pen, annual cow mortality rate, herd size, BMSCC, milk } \\
\text { yield per cow-year, organic }\end{array}$ \\
Reported treatment incidence total & $\begin{array}{l}\text { Use of hospital pen, annual cow mortality rate, herd size, BMSCC, milk yield } \\
\text { per cow-year, organic }\end{array}$ \\
Reported treatment incidence for hoof/leg disorders & $\begin{array}{l}\text { Use of hospital pen, annual cow mortality rate, herd size, BMSCC, milk yield } \\
\text { per cow-year, organic }\end{array}$ \\
\hline
\end{tabular}

Table 2 Availability of hospital pens for four different categories of animals in 130 Danish dairy cattle herds.

\begin{tabular}{|c|c|c|c|c|}
\hline Herds with & $\begin{array}{l}\text { Number of herds } \\
\text { with animals of the } \\
\text { given category* }\end{array}$ & $\begin{array}{l}\text { Percent with hospital } \\
\text { pens for individual } \\
\text { animals }\end{array}$ & $\begin{array}{l}\text { Percent with hospital } \\
\text { pens for groups of } \\
\text { animals }\end{array}$ & $\begin{array}{l}\text { Percent without hospital } \\
\text { pens for either individuals } \\
\text { or groups }\end{array}$ \\
\hline Dairy cows & 83 & 78 & 65 & 9 \\
\hline Heifers & 90 & 50 & 42 & 24 \\
\hline Males, six months or older & 52 & 82 & 45 & 12 \\
\hline Calves & 95 & 58 & 39 & 22 \\
\hline
\end{tabular}

* Individual herds may have more than one animal category.

DCD compiles information from several sources, including treatments performed by veterinarians, hoof-trimmers or farmers, and milk quality from dairies. The extracted information included the 12 months prior to the date of answering the questionnaire. The following variables were defined and calculated:

- Availability of hospital pen - a dichotomous variable of whether one or more hospital pens (either individual or group) were available in the herd;

- Use of hospital pen - a dichotomous variable of whether one or more hospital pens were in use on the particular day of answering the questionnaire;

- Annual cow mortality rate - the number of dead (unassisted or euthanised) cows per cow per year;

- Reported treatment incidence for all diseases - the number of disease treatments recorded in the DCD per 100 cows per year;

- Reported treatment incidence for hoof/leg disorders - the number of recorded treatments for hoof/leg disorders in dairy cows (including: interdigital phlegmone, sole ulcer, heel horn erosion, interdigital dermatitis, sole haemorrhage, digital dermatitis, swollen hocks, joint inflammation, digital dermatitis, interdigital hyperplasia, white line disease, and other hoof/leg disorders) per 100 cows per year;

- Herd size - the number of cow-years calculated as number of cow-days in the herd divided by 365 ; and

- Milk yield per cow-year: the average milk yield per cow per year.
Both the availability and the use of hospital pens were calculated as prevalences among respondents for each animal category. To analyse the association between availability or use of hospital pens and the incidence of reported disease treatments, four statistical models were established. The outcome and explanatory variables for each model are shown in Table 1. The additional five explanatory variables were included as they could be confounded with presence and use of hospital pens. The four models analysed data using multivariable models with stepwise backwards elimination (PROC MIXED, SAS version 9.4). We checked for confounding between additional explanatory variables and availability and use of hospital pens by checking for differences in model estimates when including or excluding one variable at a time.

\section{Results}

The questionnaires were answered and returned by 130 of 350 herd owners (response rate: 37\%). The availability of hospital pens among respondents for each animal category is presented in Table 2. Among herds with dairy cows, $47 \%$ ( 35 out of 74 responses to that question) had answered that the hospital pen for cows was in use on the day of the visit. When analysed, the association (together with the demographic variables presented in Table 1) between the availability (presence of hospital pen[s]) or the use of hospital pens (the presence of cow[s] in hospital pen[s]) and disease treatment incidence at the herd level, demonstrated a greater number of recorded treatments for hoof/leg disorders in herds with one or more cows in hospital pens at the time of 
answering the questionnaire $(P=0.006)$. The number of recorded treatments for hoof/leg disorders was $123 / 100$ cows per year in herds with cow(s) in hospital pen(s), compared with $32 / 100$ cows per year in herds without cow(s) in hospital pen(s). The three other models were nonsignificant. No confounding between additional explanatory variables and availability and use of hospital pens was seen.

\section{Discussion}

We found that, depending on the animal category, 9-24\% of the herds had no access to hospital pens, and $18-50 \%$ of the herds had no access to individual hospital pens. In general, access to hospital pens was more common for cows compared with the other animal categories. The response rate $(37 \%)$ was comparable to other similar studies with written questionnaires and no use of reminders (Laven et al 2009; Elbers et al 2010; Thomsen et al 2012). However, some selection bias may still be anticipated. Thus, farmers without hospital pens may have been less likely to answer and the proportion of herds without access to hospital pens may therefore be higher than estimated by the present study.

We propose two different theoretical explanations for a greater number of reported treatments for hoof/leg disorders in herds with cow(s) in hospital pens, although we do not have data to support these. Firstly, in herds requiring many treatments for hoof/leg disorders, it may be found necessary to make use of hospital pens, while this may not be considered as important for other diseases. Additionally, a high number of sick animals per se increase the probability of finding one or more cows in a hospital pen on any given day. Alternatively, it may be that a low treatment incidence is due to a high treatment threshold among farmers. Farmers being reluctant to treat lame animals may also find that lame animals do not need the special care provided by housing in hospital pens.

\section{Animal welfare implications}

As the availability of hospital pens was not associated with treatment incidence, care should be taken in the consideration of this as a welfare indicator. However, we can speculate that the lack of hospital pens in some herds may compromise animal welfare of sick cows needing special care. In the case of a sudden outbreak of disease or animal injury in a herd without readily established hospital pens, a delay is likely before such pens can be established, or before the animal can be euthanised or slaughtered. Thus, the lack of hospital pens runs the risk of potentially compromising animal welfare in these herds.

\section{Acknowledgements}

The study was financed by the Danish Animal Welfare Centre. We thank all the farmers that answered the questionnaires. Thanks also to Connie Hårbo Middelhede (Aarhus University) for help with data editing.

\section{References}

Anonymous 2014 Law nr 520, 26/05/2010; Ministerial order number 470 of 15/5/20/4. https://www.retsinformation.dk /pdfPrint.aspx?id=162875

Aubert A 1999 Sickness and behaviour in animals: a motivational perspective. Neuroscience \& Biobehavioral Reviews 23: 1029 1036. http://dx.doi.org/10.1016/S0149-7634(99)00034-2

Bennedsgaard TW, Jensen MB and Sørensen JT 2014 Nulpunktsundersøgelsen i kvægbesætninger i 2013. Annual Report from Ministry of Food, Agriculture and Fisheries of Denmork pp 18-23. The Danish Veterinary and Food Administration: Glostrup, Denmark. [Title translation: The baseline investigation of cattle herds in 2013] Dantzer R and Kelley KW 2007 Twenty years of research on cytokine induced sickness behavior. Brain Behavior and Immunity 21: 153-160. http://dx.doi.org/10.1016/j.bbi.2006.09.006

EIbers ARW, de Koeijer AA, Scholamacchia $F$ and van Rijn PA 2010 Questionnaire survey about the motives of commercial livestock farmers and hobby holders to vaccinate their animals against Bluetongue virus serotype 8 in 2008-2009 in the Netherlands. Vaccine 28: 2473-2481. http://dx.doi.org/10.1016 /j.vaccine.2010.01.047

Fogsgaard KK, Røntved CM, Sørensen P and Herskin MS 2012a Sickness behavior in dairy cows during Escherichia coli mastitis. Journal of Dairy Science 95: 630-638. http://dx.doi.org /10.3168/jds.2011-4350

Fogsgaard KK, Herskin MS, Gorden PJ and O'Connor AM 2012 b Survey of management and design of hospital pens at lowa dairy farms. Proceedings of the First Dairy Cattle Welfare Symposium p 2. 24-26 October 20I2, Guelph, Ontario, Canada

Huzzey JM, Veira DM, Weary DM and von Keyserlingk MAG 2007 Behavior and intake measures can identify cows at risk for metritis. Journal of Dairy Science 90: 3320-3233. http://dx.doi.org//0.3168/jds.2006-807

Jensen MB, Herskin MS, Thomsen PT, Forkman B and Houe H 2015 Preferences of lame cows preferences for type of surface and level of social contact in hospital pens. Journal of Dairy Science 98: 4552-4559. http://dx.doi.org// 0.3168/jds.2014-9203

Laven RA, Huxley JN, Whay HR and Stafford KJ 2009 Results of a survey of attitudes of dairy veterinarians in New Zealand regarding painful procedures and conditions in cattle. New Zealand Veterinary Journal 57: 215-220. http://dx.doi.org/ $10.1080 / 00480169.2009 .36904$

Proudfoot KL, Jensen MB, Weary DM and von Keyserlingk MAG 2014 Dairy cows seek isolation at calving and when ill. Journal of Dairy Science 97: 2731-2739. http://dx.doi.org/ 10.3168/jds.2013-7274

Thomsen PT, Anneberg I and Herskin MS 2012 Differences in attitudes of farmers and veterinarians towards pain in dairy cows. The Veterinary Journal 194: 94-97. http://dx.doi.org/10.101 6/j.tvjl.2012.02.025

Weary DM, Huzzey JM and von Keyserlingk MAG 2009 Using behavior to predict and identify ill health in animals. Journal of Animal Science 87: 770-777. http://dx.doi.org//0.2527/jas.2008-1 297 